\title{
ANNOUNCEMENT
}

\section{International Symposium on Milankovitch and Climate: Understanding the Response to Orbital Forcing}

\author{
Lamont-Doherty Geological Observatory of Columbia University, \\ Palisades, New York 10964 \\ December $1-3,1982$
}

This symposium is being held to evaluate the progress in understanding and modeling the mechanisms by which the climate system responds to orbital variation. The program will be organized to reflect both the recent rapid progress in numerical climate modeling and the mounting geological evidence in support of the astronomical theory.

Proposed sessions will examine (1) orbital variations and their impact on the insolation regime, (2) numerical modeling of the climatic response to orbital forcing, (3) geological record of climate in the context of the astronomical theory, and (4) recommendations for future research (final workshop).

English will be the language of the Conference. Cochairmen are:

Andre Berger, Université Catholique de Louvain, Louvain-la-Neuve, Belgium and

John Imbrie, Department of Geological Sciences, Brown University, Providence, Rhode Island

Deadline for 250-word abstract: June 15, 1982.

Mail to: $\quad$ Rose Marie Cline, Coordinator Lamont-Doherty Geological Observatory, Palisades, NY 10964

Support is being sought for publication of a symposium volume. Sponsored by:

\author{
International Commission on Climate (ICCL) \\ of the \\ International Association of Meteorology and \\ Atmospheric Physics (IAMAP) \\ and \\ The Paleoclimatic Commission of INQUA
}

